\title{
Intercultural Knowledge Development During Short-Term Study Abroad in the Basque Country: A Cultural and Linguistic Minority Context
}

\author{
Ager Gondra \\ University of Miami
}

Lori Czerwionka

Purdue University

\begin{abstract}
:
This investigation examined intercultural knowledge development in a short-term study abroad program in a cultural and linguistic minority context (Basque Country, Spain). A pre- and postprogram quantitative and qualitative design was used with 26 participants. The quantitative, surveybased results demonstrated an increase in intercultural knowledge over the study's five-week duration. Qualitative analysis of interview data indicated that students' intercultural knowledge aligned with Lussier's (2007) description of knowledge about "small c" culture and included knowledge of social groups-a distinct finding from prior research. Students' knowledge changed over the period abroad, indicating adjustment to City Life and Time and Schedule norms. Additionally, knowledge growth was greatest with respect to subthemes strongly linked to the minority context (e.g. Basque ethnicity, culture, language). This study offers detailed information about intercultural knowledge development during short-term study abroad experiences and demonstrates that minority context programs encourage development of intercultural knowledge about "small c" culture and social groups.
\end{abstract}

\section{Introduction}

Study abroad promises new experiential and learning opportunities for students. Many positive outcomes have been associated with study abroad such as improvements in one's linguistic and communicative resources (Dings, 2007; 2014; Kinginger, 2008; Lafford, 1995; Segalowitz \& Freed 2004), personal growth (Black \& Duhon, 2006), opportunities for reevaluation of academic and career choices (Malmgren \& Galvin, 2008), and intercultural learning (Dwyer, 2004; Jackson, 2011; Martinsen, 2011). Yet, study abroad does not always provide a more impactful learning experience compared to at-home environments (Collentine, 2004; De Keyser, 1990), and pedagogical interventions may be required for certain types of learning during study abroad (Vande Berg, Paige, \& Lou, 2012).

Considering that the impact of study abroad on students' learning is still under debate, the current article focuses on intercultural knowledge development during study abroad. Relying on definitions by Byram (1997), Stier (2006), and Lussier (2007), intercultural knowledge is information and 
understandings related to one's own and one's interlocutor's country or culture, and broadly includes "historical and current information, processes and practices related to social groups and individuals, along with comparative perspectives and knowledge of the cross-cultural learning process" (Czerwionka, Artamonova, \& Barbosa, 2015, p. 81). Study abroad has been shown to positively impact students' knowledge (Elola \& Oskoz, 2008; Engle \& Engle, 2004). Yet despite overall knowledge growth during study abroad, some areas of knowledge are lacking, specifically knowledge of social groups and also cross-cultural learning and adjustment trends (Czerwionka et al., 2015). The lack of growth with respect to these knowledge types was found when examining a short-term, languagelearning, study abroad program in Madrid, Spain (Czerwionka et al., 2015). The goal of this study is to examine intercultural knowledge growth during a similar, short-term, language-learning program, but one that takes place in a minority context- the Basque Country, an ethnically and linguistically diverse community in northern Spain. The development of students' intercultural knowledge is quantitatively and qualitatively analyzed using survey and interview data taken at the beginning and end of the program. It is questioned whether and in what ways the minority context impacts the types of intercultural knowledge developed by students. The results of this study provide heightened understanding of the benefits of a short-term program in a minority context in terms of intercultural knowledge growth.

We examine intercultural knowledge growth in a minority context in the Basque Country, Spain, because for American students studying abroad, Spain represents the third most popular country overall and the most popular country for study abroad among Spanish-speaking countries (The Institute of International Education). Institute data shows that in 2016, a total of 26,949 American students studied in Spain. Therefore, given the number of students who study abroad in Spain, it is particularly important to examine the outcomes of these programs.

\section{Literature review}

Various models of intercultural development, while at times using distinct terminology, agree that knowledge, skills, and attitudes are primary components (Bennett, 1993; Bennett, 2008; Deardorff, 2006; Gertson, 1990; Gudykunst, Ting-Toomey, \& Wiseman, 1991). Many other characteristics have also been shown or theorized to be important in the development intercultural competence, such as flexibility, openness, awareness, empathy, tolerance for ambiguity, and respect, among others (e.g. Byram, 1997; Ruben, 1976; Risager, 2007). In this paper we rely on insight from various theories (e.g. Intercultural Communicative Competence, Intercultural Competence, Intercultural Communication) in order to frame intercultural knowledge within a developmental and context-based perspective of intercultural communicative competence. Theoretically, intercultural competence is developmental in that change over time is possible (Bennett, 1993). Bennett's (1993) Developmental Intercultural Competence Model describes ethnocentric to ethnorelative stages of development. Furthermore, changes in intercultural communicative competence or the related knowledge, skills, and attitudes depend on the surrounding context; Ting-Toomey (1999) argues that interactions occur among the contextual variables initially present in an intercultural situation, the processes that change those variables, and the resulting variables that have been impacted by the context. The importance of context is also reflected in study abroad research broadly, exemplified by the call to examine the impact of individual student variables, programmatic details, and interactions with host communities on study abroad outcomes (e.g. Kinginger, 2008). 


\section{Intercultural Knowledge}

Deardorff (2006) defines intercultural knowledge as a subcomponent of intercultural communicative competence and states that knowledge contributes to one's "ability to communicate effectively and appropriately in intercultural situations" (p. 247-248). Knowledge enhances one's anticipation of conversational topics, interlocutor ideas and stances, and ways of interacting. Knowledge improves accurate predictions about the culture (Wiseman, 2002), and cultural knowledge improves the understanding of culturally-constrained behaviors (Wiseman, Hammer, \& Nishida, 1989). Aligning with these views, Czerwionka et al. (2015) relied on the dialogic theory of Anticipatory Schemata (Caffi \& Janney, 1994) to highlight the notion that intercultural knowledge shapes interlocutors' expectations about how people interact, and about conversational or ideological norms associated with certain conversational topics. While this view specifically points to the importance of knowledge in enhancing intercultural communication, superior intercultural communicative competence also provides more opportunity for intercultural knowledge growth. As stated by le Roux (2002), "[c]ommunication may be a useful source of intercultural knowledge” (p. 38).

Various studies have examined knowledge developed during study abroad programs, but few have provided a pre- and post-test approach. Of those studies that examined post-program evaluations of knowledge, Chieffo and Griffiths (2004) examined the experiences of 1,509 students with a survey instrument and an open-ended question about the most important thing learned during study abroad. They found that students most often commented on knowledge that they had developed during the programs such as "knowledge/appreciation of another country or culture" "course-related knowledge", and "differences between home and host country" as examples (p. 173). In another investigation, examining 204 students' responses to open-ended questions about intercultural knowledge and skills, Williams (2009) found that students who studied in short-term programs in Europe commented on their changes in knowledge, with responses indicating that students gained a "better understanding of their hosts, their habits, traits, values, or lifestyles" (p. 295). Specific areas of knowledge growth included political issues, history, international issues, and cultural values. In comments related to skills and behaviors, students also indicated knowledge related to city life, public transportation, living spaces, personal space, schedule norms, and food. Finally, in a study of a semester-long study abroad program, Elola and Oskoz (2008) identified knowledge related to "important facts about living in the other country and about the country, state, and people" and "differences and similarities between countries" (p. 467). These investigations have begun to show that intercultural knowledge is an outcome related to study abroad, including short-term programs, and both Chieffo and Griffiths (2004) and Elola and Oskoz (2008) indicated additional benefits for study abroad versus at-home groups. At the same time, these studies fall short, not only in the lack of a pre-and post-test design, but in terms of a more detailed understanding including increased knowledge related to culture, hosts, the country, or cultural differences beyond the broad findings. Furthermore, given the understanding that knowledge is a component of intercultural communicative competence, it is fundamental to consider how knowledge is expressed via the second language, since many people use a second language when attempting "to communicate effectively and appropriately in intercultural situations" (Deardorff, 2006, p. 247-248).

Responding to some of these critiques, Czerwionka, Artamonova, and Barbosa (2014; 2015) examined intercultural knowledge development using a pre- and post-test design. Quantitative and qualitative data were analyzed to investigate questions related to intercultural knowledge change and 
growth. Examining intercultural knowledge, attitude, and skills through a survey design during a sixweek, short-term program abroad in Madrid, Spain, Czerwionka et al. (2014) showed significant gains in intercultural knowledge with $97 \%(n=31)$ of students experiencing gains. Interviews with students who gained the most knowledge based on the quantitative data indicated knowledge growth related to factual information and experiences not part of daily life and more in-depth knowledge of daily experiences.

Through a grounded approach to the analysis of interviews with 37 students in their second language, Spanish, Czerwionka et al. (2015) found students expressed 13 knowledge themes (Big C, City Life, Climate and Landscape, Daily Life, Food and Drink, House, Interactions, People, Relationships, Schedule, Talk, Transportation, and Values and Politics) and 151 knowledge subthemes. The detailed analysis not only provided information about the types of intercultural knowledge held by students during study abroad, but analysis addressed intercultural knowledge change and growth over the period abroad. Important findings were that distinct patterns of knowledge change occurred; for example, knowledge related to City Life and Schedule were more salient at the beginning of the program than at the end, and the other 11 themes were more salient at the end of the program. The greater salience of some types of knowledge at the beginning of the program was attributed to the initial shift in context from the United States to Spain, which caused immediate personal impact on the students related to their own life and schedules (e.g. navigating public transportation, feeling hungry as a result of schedule differences). The reduced salience of these themes by the end of the program was taken as an indicator of adjustment to these ways of being. In terms of knowledge growth, measured by quantifying the knowledge subthemes that newly appeared in post-program interviews compared to the students' preprogram interview, growth was identified within each of the 13 themes.

Comparing the types of knowledge gained by students to definitions of intercultural knowledge, Czerwionka et al. (2015) found an absence in knowledge related to cross-cultural learning and macrosocial groups, such as class, age, race, or ethnicity. Definitions of intercultural knowledge include knowledge of social groups (Byram, 1997), sociocultural data such as class and sex (Lussier, 2007), and sex roles within society (Stier 2006), yet students did not mention these topics. In fact, these areas of knowledge were not highlighted in other studies of intercultural knowledge during study abroad (Chieffo \& Griffiths, 2004; Elola \& Oskoz, 2008; Williams, 2009), indicating a potential gap in the type of knowledge typically developed during study abroad. Thus, an overarching question related to the current study is how study abroad in a minority context impacts intercultural knowledge development, with special attention paid to knowledge about the social environment. Study abroad literature has addressed the impact of students' sociocultural identities on study abroad outcomes (e.g. Twombly, 1995; Talburt \& Stewart, 1999; Jessup-Anger, 2008) but, to the researchers' knowledge, has not addressed the impact of study abroad in a minority context on intercultural knowledge development.

\section{Towards the current study: Intercultural knowledge in a minority context}

Replicating Czerwionka et al. (2015) in the use of the quantitative measure of intercultural knowledge as well as the interview procedure and qualitative thematic analysis of intercultural knowledge change and growth, the goal of this investigation is to examine the effect of short-term study abroad on intercultural knowledge, specifically considering study abroad in a minority language and culture context (i.e. Basque Country in Spain). Four research questions guided the analysis: 
1. Do survey data provide evidence of an increase in intercultural knowledge over the shortterm program abroad?

2. What types of intercultural knowledge do students express in interviews?

3. Is there a change in the knowledge expressed by students at the beginning and end of the program? How can the change be qualified?

4. In what knowledge areas do students experience knowledge growth as evident in new knowledge shared at the end of the program?

\section{Methods}

Students' intercultural knowledge development was measured by analyzing quantitative and qualitative data in a pre- and post-test design. A portion of Fantini and Tirmizi's (2006) Assessment of Intercultural Competence questionnaire was used for the quantitative measure of intercultural knowledge. Qualitative data was obtained through semi--structured interviews that took place at the beginning and end of the short-term study abroad program.

\section{Participants}

Of the 26 students, 20 were female and six were male. All were U.S. students at a public university near New York City, and all spoke English as their native language. Students were intermediate and advanced speakers of Spanish. Students' Spanish level was determined based on their prior level of course completed or the WebCAPE Foreign Language Placement Exam. None of the students had been in the Basque Country or in Spain previously.

\section{Program Description}

The five-week summer program, directed by the first author, was located in the Basque Country, Spain: students lived with host families in Bilbao and studied in a college in Mungia. The Basque Country is located in the north of Spain, far in distance from the typical Spanish clichés or stereotypes, such as flamenco dancing and bullfighting, which are most common in southern Spain. The Basque Country has its own traditional culture, resulting from an ancient presence in the Iberian Peninsula (currently Spain and Portugal) long before the arrival of the Roman Empire. Basque culture includes a rich and colorful mythology; In ancient times their land was supposed to have been peopled by a race of giants called jentillak and female sprites called lamiak. Basque folklore encompasses various rituals, dances, and sports. Basque folk music is sung and played on traditional instruments including the txistu, a three-holed flute, and the bagpipe-like dultraina. Dozens of folk dances have been preserved, and many villages have folk-dance groups that perform regularly. Two especially spirited dances are the Bolant Dantza (flying dance) and Espata Dantza (sword dance). The Basque national game is pelota, a game like handball or squash played at very high speeds; The game has been played for centuries in an outdoor court called frontón, which often shares a wall with the village church. Additionally, the Basques are known for their excellent cuisine, and the single most distinctive item of traditional Basque clothing is the flat, wide, black beret worn by Basque men. Basque people even have their own language called Euskera, which is Europe's oldest living language. It is unrelated to Spanish, French, or any other Romance language and belongs to no other known language family. Euskera has, like Spanish, the status of an official language in the Basque Country. It is commonly used in the education system and politics, and according to the 2012 language proficiency census, $49.4 \%$ of the population is bilingual (Basque and Spanish). Finally, a Basque nationalistic movement 
exists in the Basque Country, which asserts that Basques are a nation and promotes the political unity of the Basques. Since its inception in the late 19th century, Basque nationalism has included separatist movements. Bilbao, capital city of the province of Biscay, is one of the largest cultural and economic centers in northern Spain. With a population of some 400,000 people and a large metropolitan area, the former industrial city of Bilbao has become a modern city. Mungia, on the contrary, is a nontouristy town with a population of 17,000 inhabitants and is located about 19 kilometers (11.8 miles) away from Bilbao. Studying in this town facilitates interaction with locals and provides an experience that is in isolation from other international tourists.

While in the minority context of the Basque Country during the five-week program, students reinforced their Spanish language skills and knowledge of Spanish culture by taking: one Spanish Language class, and one course on Iberian Culture(s). In the Spanish Language class students practiced and developed speaking, listening, reading, and writing skills. In the Iberian Culture(s) class, in which Spanish was the language of instruction, they explored the diversity of the cultures and languages in Spain. This course covered the 12 autonomous communities, which are political divisions in Spain, and two days were dedicated to the Basque Country. The former course was taught by a professor from the local college, while the latter was taught by the first author. Both courses met five times per week; The Spanish language course met for three hours each day, while the Iberian Culture course met for an hour and thirty minutes. Students also had a Spanish conversation hour twice a week with local students. Additionally, the program offered a good number of guided excursions to historically significant cities and towns in the Basque Country, such as San Sebastian, Gernika, Mundaka, Bermeo, Bakio, San Juan de Gaztelugatxe, and Plentzia, as well as Madrid, Segovia, and Pamplona, which are cities in other autonomous communities in Spain.

\section{Instruments}

The current mixed-methods approach relied on a survey instrument and an oral semi-structured interview, both of which are detailed below.

\section{Survey}

The survey instrument originated from the Assessing Intercultural Competence questionnaire (see Fantini \& Tirmizi, 2006, Appendix G for the original instrument.) Whereas Czerwionka et al. (2014) used this survey to assess intercultural knowledge, attitude, and skills, this study focused only on intercultural knowledge, as this is where Czerwionka et al. (2014) observed the most prominent growth. The intercultural knowledge questionnaire used Fantini and Tirmizi's (2006) 11 statements about knowledge, and participants indicated their level of agreement with each statement using a 7point Likert scale, ranging from strongly disagree (1) to strongly agree (7) (see Appendix A).

\section{Interview}

The semi-structured interview in this study was based on the one used in Czerwionka et al. (2015). It consisted of pre-planned questions related to six general topics: College, Family, Living arrangements and life, Opinions and cultural comparisons, People, and Feelings, achievements and advice (Appendix B). The interview followed question-ordering norms progressing from introductory questions to more specific ones (Tagliamonte, 2006). Some questions addressed cultural differences since noticing and understanding cultural differences is fundamental to the development of intercultural communicative competence (Byram, 1997). Other questions focused on students' 
development and achievements in order to explore students' cross-cultural learning and adjustment trends. The interview topics were selected to align with definitions of intercultural knowledge. All interviews were conducted in Spanish. Czerwionka et al.s $(2014 ; 2015)$ findings show that the use of Spanish is not an impediment for students to express intercultural knowledge, and they claim that using the second language is a "valid approach to investigate intercultural knowledge for this population of learners" (p. 84). Considering that intercultural communication often occurs via the second language of at least one interlocutor, second language intercultural communicative competence (L2 ICC) should be the object of analysis where applicable.

\section{Procedures}

Students completed the questionnaire on paper on the first day of class, which was their fourth day in Spain. The last day of class students filled out the questionnaire on paper for the second time.

Interviews were conducted at the beginning and the end of the program. The first interview was recorded the first day of class and the second interview the last day of class. All interviews lasted between 30 and 45 minutes, with a total of 15 hours and 6 minutes of data in the first round of interviews (Interview 1) $(M=34.85, S D=2.62)$ and 15 hours and 35 minutes in the second round (Interview 2) $(M=35.96, S D=3.27)$. There was no significant difference in length between the two sets of interviews $(t=-1.232, p=0.229)$.

Five local students from the Basque Country were the interviewers. Four of them interviewed five students each, while the fifth interviewed six students. The interviewers interviewed the same students in both sessions. All five interviewers were native speakers of Spanish and had a B.A. degree in English. Before Interview 1, the first author informed them about the goals and structure of the interview. Additionally, the first author asked them to rephrase the questions and pose follow-up questions to encourage students' participation if necessary. The interviews were semi-structured because even though the interviewers asked pre-planned questions, topics beyond the interview questions could also be addressed (Eckert, 2000).

\section{Approach to Analysis}

In order to respond to research question 1, a paired t-test considering the effect of time (i.e. preand post-program) was conducted on the results obtained from the intercultural knowledge questionnaire. The statistical analysis was conducted with JMP. In addition, an analysis of intercultural knowledge growth by student was conducted.

In response to research questions 2, 3, and 4 about intercultural knowledge types and intercultural knowledge change and growth over the program, interviews were transcribed, data were coded using intercultural knowledge themes following a grounded approach to qualitative, thematic analysis (Corbin \& Strauss, 2008; Glaser \& Strauss, 1967), and a measure of student mentions was calculated. In this type of qualitative analysis, themes are identified, hierarchically organized (e.g. themes and subthemes), and reconsidered and recoded as coding of more data occurs. The process is iterative so that the final organization of themes best matches the data. The measure of student mentions was calculated by counting the number of students who mentioned a given subtheme in a given interview. If the student made the same comment more than once within the same interview, the comment was only counted as one mention of the theme for the final counts. Of the 342 total comments in 
Interview 1 and of the 674 total comments in Interview 2, 300 and 586 were counted respectively. Student mentions were used to understand common themes and subthemes and to identify intercultural knowledge change and growth over the program. Individual student comments were then selected to exemplify the intercultural knowledge change and growth identified.

\section{Results}

\section{Quantitative Results}

The pre- and post-program questionnaires from 26 students resulted in a total of 54 complete questionnaires. A paired t-test examining the effect of time (i.e., pre- vs. post-program) on students' intercultural knowledge was conducted. As in Czerwionka et al. (2014), a Bonferroni adjustment was made setting the alpha value at .0125. Results showed that there was a significant effect for time on students' intercultural knowledge, $t=-12.71, p=<.0001$, with students indicating less knowledge at the beginning of the program $(M=3.1, S D=0.75)$ than at the end of the program $(M=5.7, S D=$ 0.74). Figure 1 illustrates the response means (1-7 Likert scale, with 7 being strongly agree).

Figure 1. Intercultural knowledge growth.

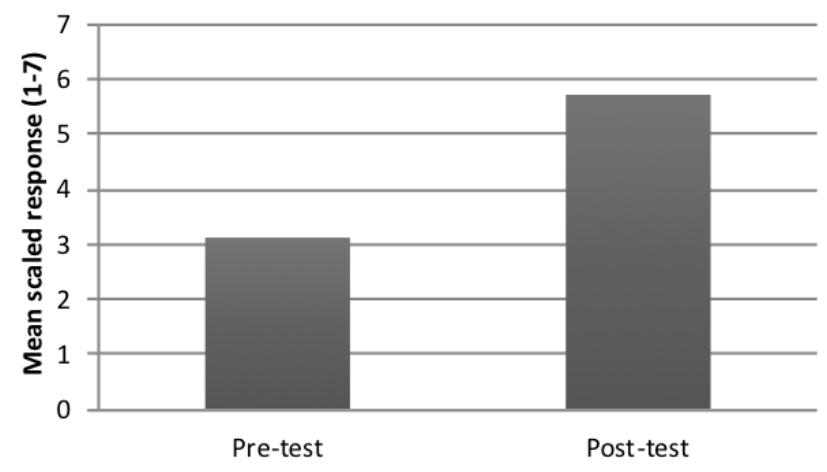

The difference between the pre- and post-program intercultural knowledge scores for individual students indicated that all students experienced intercultural knowledge growth. Figure 2 represents individual students' growth in intercultural knowledge, calculated by subtracting the pre-program score from the post-program score. Intercultural knowledge growth, measured quantitatively, ranged from 1.5 to 4.4 points on the seven-point scale $(M=2.6, S D=0.74)$.

Figure 2. Intercultural knowledge growth by individual student.

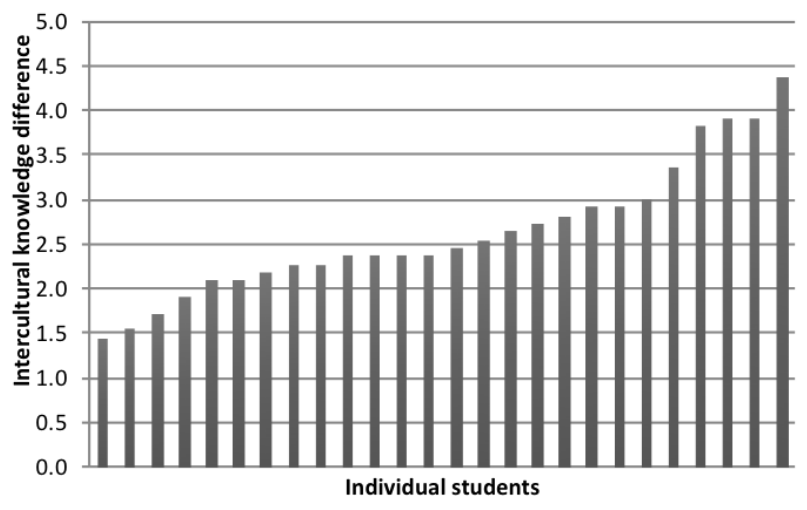




\section{Qualitative Results}

Sections 4.2.1, 4.2.2., and 4.2.3 respond to research questions 2,3 and 4 respectively. Section 4.2.4 shows selected student comments that illustrate the areas of knowledge change and growth in students' own words.

\section{Knowledge areas: Themes and subthemes}

In order to identify the types of intercultural knowledge students expressed in Interview 1 and 2 (research question 2), student mentions of the knowledge themes from both interviews were summed together. Within the 892 total coded comments, there were 14 themes. As Figure 3 illustrates, the most common themes were City Life, Daily Life, Gastronomy, Languages, and People.

Figure 3. Total student mentions of subthemes by theme in Interview 1 and 2 collectively.



Within the 14 themes, there were a total of 125 subthemes. Under City Life, there were subthemes such as monuments and museums, description of the streets, buildings and houses, the size of the cities and towns, and the different types of flags in Madrid versus the Basque Country. Climate and Landscape covered topics related to weather, landscape descriptions, and water temperature. The theme Daily Life addressed observations about the slow pace of life, ways and places to socialize, siestas (naps), notions of fashion, and the tendency to eat with other people. While talking about Gastronomy, students mentioned names of foods and drinks, the difference between tapas 1 and pintxos2, the ingredients and preparations of some dishes, and they argued that bread is always part of every meal and that breakfasts are sweet, not salty. Geography covered the names of Autonomous Communities,

\footnotetext{
${ }^{1}$ Tapas are small appetizers (e.g. olives, potato chips, ham on a small piece of bread) that Spaniards typically eat in bars before dinner. Traditionally, they are served for free with every drink bought.

2 Pintxos, which are part of the Basque gastronomy, are appetizers such as fish, peppers, or even more creative culinary choices that are served on a thick slice of bread. As opposed to tapas, pintxos are typically larger, and they are not free. Bars display their selection of pintxos on the counter.
} 
touristic cities, non-touristic cities and towns, and beaches. Another theme was Identity, where diversity and Spanish, Basque, Catalan and even Galician identity were discussed. Students also associated some cultural aspects and people's appearance with identity. Comments about Interactions addressed the way of greeting, less personal space, and directness and a low tone of voice while talking. Similar to the theme of interactions, but more focused on Language, students talked about the linguistic diversity in Spain, linguistic characteristics of Basque, different Spanish dialects, bilingualism, and expressions and words they learned in Spanish and Basque. Students expressed knowledge related to Spanish and Basque Music, Dance and Sports. Students also gave a description about Basque People based on their experiences with them. Regarding Politics, students pointed out the Basque independence movement, and also defined Spain as a liberal country compared to the United States. Religion and Mythology was another theme that emerged as students addressed Catholicism and Basque mythology. Students shared their confusion about Time and Schedule. They could not understand why people eat late but drink early, why they sleep after lunch, why stores close during lunchtime, and why public transportation stops running at night. Finally, Transportation comments contrasted the use of Spanish public transportation and its efficiency as opposed to the limited use of this transportation method and its inefficiency in the United States.

The quantity of subthemes varied depending on the theme. Whereas there were only three subthemes within the theme Religion and Mythology, 19 subthemes were identified within the theme People. There was also a variation in the number of mentions within each subtheme. Some subthemes like Slower pace of life, Nice/Friendly people, Ethnicity, Basque nationalism, and Streets were mentioned quite often in the interviews (Table 1), while 23 subthemes were addressed only once. All themes and subthemes, along with the counts of student mentions, are listed in Appendix C.

Table 1. Counts of student mentions for the top 15 subthemes in interviews 1 and 2 collectively.

\begin{tabular}{ll}
\hline Subtheme (n) & Theme \\
\hline Slower pace of life (31) & Daily Life \\
Nice/Friendly (27) & People \\
Ethnicity (24) & People \\
Basque nationalism (20) & Politics \\
Streets (19) & City Life \\
Food preparation/ingredients (19) & Gastronomy \\
Traditional food (19) & Gastronomy \\
Touristic cities (19) & Geography \\
Pintxos (18) & Gastronomy \\
Basque linguistics (18) & Language \\
Diversity (17) & Identity \\
Spanish dialectology (17) & Language \\
Stores (17) & Time and schedule \\
Buildings (16) & City Life \\
Liberals (16) & Politics
\end{tabular}




\section{Knowledge change}

In order to know the ways the interviews exhibit change in intercultural knowledge comparing the expressed knowledge themes at the beginning and end of the program (research question 3), a comparison of the student mentions by theme in Interview 1 and Interview 2 was made. Each individual's mentions of subthemes were classified by separating those occurring in Interview 1 from those in Interview 2. Figure 4 provides descriptive findings by contrasting student mentions at the beginning and end of the program.

Figure 4. Sums of student mentions of subthemes by theme in Interviews 1 and Interview 2

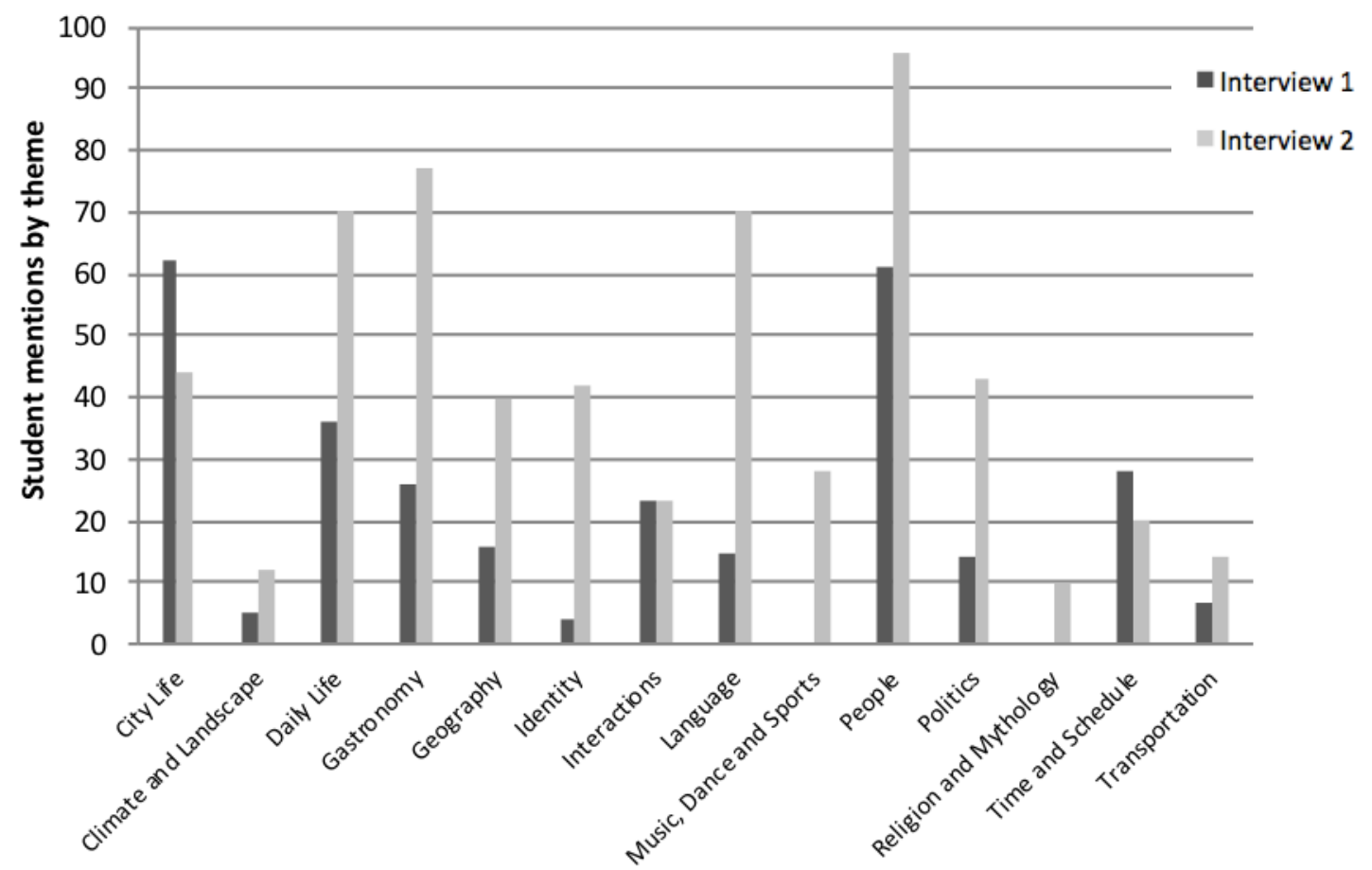

Figure 4 shows three change patterns: Decrease, no change, and increase in mentions over the program. The first pattern, decrease, occurred with the themes City Life and Time and Schedule. City Life and Time and Schedule were knowledge areas that were more salient to students at the beginning of the program compared to the end. The second pattern, no change, happened with the theme Interactions. Students had the same number of comments about Interaction subthemes at the beginning and end of the program. The third pattern of increasing mentions over the program was observed in the remaining themes.

\section{Knowledge growth}

To find the percentage of knowledge growth that the students experienced in each area (research question 4), new knowledge expressed in Interview 2 by theme was calculated. New knowledge was defined as knowledge mentioned in Interview 2 that was not mentioned by the student in Interview 1.

Knowledge growth took place in all 14 themes (Table 2). However, this growth occurred at different levels depending on the theme. Students commented often on subthemes about Daily Life, 
Gastronomy, Language, and People (see Figure 4), but the new knowledge observed varied among them. For instance, even though People was the most addressed theme, there was a higher rate of new knowledge related to Gastronomy. Additionally, Daily Life and Language were quite equally mentioned in Interview 2, and yet, there was a greater knowledge growth related to Language. Students barely mentioned new subthemes related to Time and Schedule in Interview 2, representing the lowest knowledge growth of all themes (15\%). On the contrary, the greatest knowledge growth occurred with Music, Dance and Sports (100\%) and Religion and Mythology (100\%), as they were not addressed at all in Interview 1, and therefore, all student comments related to these two themes in Interview 2 were considered new knowledge. Appendix D lists all subthemes considered new knowledge.

Table 2. Percentage of knowledge growth by theme

\begin{tabular}{ll}
\hline Theme & Knowledge growth \\
\hline City Life & $45.5 \%$ \\
Climate and Landscape & $58.3 \%$ \\
Daily Life & $52.9 \%$ \\
Gastronomy & $81.8 \%$ \\
Geography & $82.5 \%$ \\
Identity & $91.3 \%$ \\
Interactions & $52.2 \%$ \\
Language & $92.9 \%$ \\
Music, Dance, and Sports & $100.0 \%$ \\
People & $63.5 \%$ \\
Politics & $76.7 \%$ \\
Religion and Mythology & $100.0 \%$ \\
Time and Schedule & $15.0 \%$ \\
Transportation & $57.1 \%$
\end{tabular}

\section{Student Comments}

Bearing in mind the results of the prior steps of analysis, this section presents student comments translated into English that illustrate areas of knowledge change and growth. The comments in this section represent three specific findings: themes that were more salient to students immediately upon arrival to the Basque Country at the beginning of the program, themes where the greatest intercultural knowledge growth occurred, and themes exhibiting knowledge growth specifically related to the Basque Country as a place of cultural diversity in Spain.

Salient intercultural knowledge at the beginning of the program

There was no intercultural knowledge growth in City Life and Time and Schedule as they were mentioned more often in Interview 1 than Interview 2 by the students. City Life and Time and Schedule were important when the students arrived, but became less important by the end of the program. The following student comments show the students' first impressions of their new location. For instance, regarding City Life, in the first interview students often pointed out the style of the streets, how all of them had names instead of numbers, and that their names were written on buildings instead of on posts (Comments 1-3). They also often commented on the historical buildings (Comment 4), houses where they were staying (Comment 5), and perceived cleanliness and safety situations (Comments 67). 
Comment 1:

'Here streets are like labyrinths. I got lost some many times at the beginning of the program.... I enjoyed getting lost in them though! They are beautiful, full of history... that's how I pictured European streets, small streets, made of cobblestones...'

Comment 2:

'I'm used to using numbers to address streets. In New York City every time I want to meet with someone I would say, "let's meet between Third Avenue and 14th Street", for example. But in Bilbao streets do not have numbers, but names, which makes it very difficult to memorize all those names! I still sometimes have to ask my Basque family where a certain street is.'

Comment 3:

Ok, this is funny. I remember the first weekend in Bilbao trying to figure out where I was. I was trying to find the post with the name of the street... you know, in the United States, in every street corner you have a post showing the number of the street. Well, I couldn't find it! A couple of days later, I pointed a plate on the wall of a building and said, "isn't it weird that the name of the street is indicated on the building?' And I was like "OMG..."

Comment 4:

'There are so many historical buildings in Spain. Everywhere that I look, I see a historical building. In the United States we have "historical" buildings" and we think they are old. But if you think about it, the United States is a new country, and the buildings are not so old... here in Europe you find real historical buildings, really old. Walking in the streets is like traveling in time'

Comment 5:

'I have a house in the US and I live in a neighborhood. Here I live in an apartment in a building and in the city. The apartments are quite small. I guess you can compare it with New York City, where most people live in tiny apartments.'

Comment 6:

'Here everything is cleaner than the United States! The streets are clean, the subway is clean..., I haven't seen a person throwing trash on the floor'

Comment 7:

'I feel safe here. When I'm walking home at night, I don't think something bad is going to happen to me. I mean, I don't think someone is going rob me, for example. I don't even hear police sirens. I don't even see policemen. I can be alone and it's fine'

With respect to Time and Schedule, students in the first interview constantly contrasted their experience with time and schedule during the summer program with their time and schedule in the United States. Most of the student comments reflected students' irritation with stores closing during lunchtime and the subway closing at night (Comment 8-9). Some student comments also showed 
that meals were late compared to their U.S. norms (Comment 10).

Comment 8:

'I love European fashion, so on Sunday I decided to go shopping to buy some European clothes, but I couldn't because all the stores were closed! I didn't understand why, I thought something happened.... I don't know, maybe it was a holy day or something. So, I decided to go the next day after lunch, but the stores were still closed! It was so strange. Then I found out that the stores here close on Sundays and during lunchtime, from 1 p.m. to 5 p.m. more or less. I mean, really? When am I supposed to go shopping? In the United States, especially in NYC, stores do not close on Sundays. And even less during lunchtime. What am I supposed to do with I need to buy something at 3 p.m.? Or on Sunday?' Ugh! This is so annoying...'

Comment 9:

'Public transportation stops running way too early. I don't live in downtown Bilbao, so on Fridays I need to make sure I catch the last subway, which is around $11 \mathrm{pm}$. People here use the public transportation a lot, so I don't understand why the subway is not running all night, or at least until later than 11 p.m.'

Comment 10:

'People here have dinner late, but then they do everything later, they have breakfast and lunch later and they go to bed later, so I guess it makes sense.'

Greatest intercultural knowledge growth

The greatest intercultural knowledge growth occurred in Music, Dance and Sports and Religion and Mythology; 100\% of the student comments in Interview 2 represented new knowledge in these areas as they were not mentioned at all in the first interview. Student comments demonstrated that they learned to be able to distinguish more stereotypical examples of Spanish culture like bullfighting and flamenco music and dancing from the Basque music, dances and sports (Comment 11-12).

Comment 11:

'Before coming here, I thought the traditional music and dance in all Spain was flamenco, but it turns out that I was completely wrong. I have been here for almost five weeks and I have never listened to or seen flamenco in the Basque. It does not exist here. It feels like it belongs to a different country or something like that. In the Basque Country they have their own traditional music and dances. They play their music with their own Basque instruments... I don't know the names of the instruments, but for example it's like a flute that you just hold with one hand, and like a drum that you play with the other hand. The person plays both at the same time. Basque dances are very different, too. They dance lifting their legs; they don't move their hips.

Comment 12:

'Soccer is big in Spain; it's the most famous sport. The soccer team in Bilbao is Athletic de Bilbao.... But in the Basque Country they have different sports. There are Basque sports that seem very old. They measure mainly their strength, but some of the sports also are about 
speed. I heard about Jai Alai, they play it in some parts of the United States, but I didn't know it was originally Basque. The other day I saw a Jai-Alai game, and I was shocked when I saw that they were using one wall of a church to play the game'

Almost all student comments about Religion and Mythology addressed Basque mythology (Comment 13). Very few comments were about Catholicism (Comment 14).

\section{Comment 13:}

'Basque had a matriarchal religion before they were converted into Catholicism. Their goddess was Mari. Besides Mari, there was also her husband, who was half-man half-snake, Olentzero, that is like Santa Claus in the United States, Mermaids with goose feet, giants and witches.'

\section{Comment 14:}

'In Spanish the dominant religion is Catholicism. In the United States there are different branches of Christianity, but here there is only Catholicism.'

Basque cultural knowledge growth

Other themes involving a greater rate of knowledge growth, with between $92.9 \%$ and $81.8 \%$ of comments during Interview 2 being new information, were Gastronomy, Geography, Identity and Language. The most salient subthemes within these themes were Basque gastronomy, Basque geography, Basque identity, and Basque language (Comment 15-18). These four subthemes, along with the ones shown in comments 11-13, illustrate knowledge growth strongly associated with the Basque Country.

Comment 15:

'In the Basque Countries they don't have tapas, but pintxos. Like the tapas, you can get pintxos at the bar and you normally eat with it a drink, but you have to pay for the pintxos while tapas are normally free. The bartender gives you a tapa when you buy a drink.'

Comment 16:

'I've been in cities, like San Sebastian and Pamplona, but also in small towns like Gernika, Mundaka, Plentzia and Bakio. Last weekend my Basque family took me to Biarritz, which is the Basque territory in the French side.'

Comment 17:

'Before I came here, I thought that everyone from Spain felt Spaniard, and that they were proud of being from Spain. Here I learned that some Basques do not consider themselves Spaniards, but Basques. 'This does not happen only with Basques, but also with Catalans.'

Comment 18:

'I knew there was another language in Spain besides Spanish. I had heard that Catalan was spoken in Catalonia, but I didn't know that Basque even existed. Now I know that Basque is a language spoken in the Basque Country and that it has nothing do with Spanish.'

\section{Discussion}

This section relies on the results to answer the four research questions. Findings from the current 
study of intercultural knowledge development in a minority context of study abroad (Basque Country, Spain) are also contrasted with the findings in Czerwionka et al. (2014; 2015) representing students who studied abroad in Madrid, Spain.

\section{Increase in intercultural knowledge}

Examining the pre-program quantitative results from the intercultural knowledge survey data, students began the program with positive levels of intercultural knowledge $(M=3.1, S D=0.75)$. Since the students who participated were Spanish majors and minors, and therefore had studied the language and associated cultures for many years, this high score may be due to their previous classroom experiences. Previous research has suggested that classroom experiences have a positive impact on intercultural knowledge (Hoyt, 2012; Czerwionka et al., 2014). Additionally, Czerwionka et al. (2014) suggested that high levels of intercultural communicative competence may be a defining characteristic of dedicated language and culture students who choose to participate in study abroad programs.

Comparing the post-program results with the pre-program results, students almost doubled their level of intercultural knowledge by the end of the program $(M=5.7, S D=0.74)$, making significant gains in intercultural knowledge over the five-week period. Furthermore, contrasting these results with the survey data in Czerwionka et al. (2014), both groups, one in the minority context (Basque Country) while the other in the dominant context (Madrid), started with different levels of intercultural knowledge, $(M=3.1, S D=0.75)$ and $(M=4.6, S D=0.42)$ respectively, but their end numbers were similar, $(M=5.7, S D=0.74)$ and $(M=5.8, S D=0.46)$. This seems to indicate that short-term programs have similar end results regardless of the program, according to this measure of intercultural knowledge for varying populations of students. More interestingly, these results indicate that shortterm study abroad is more beneficial in terms of intercultural knowledge growth for students who have lower levels of intercultural knowledge initially.

\section{Types of intercultural knowledge}

The type of intercultural knowledge expressed by students in Interview 1 and 2 were City Life, Climate and Landscape, Daily Life, Gastronomy, Geography, Identity, Interactions, Language, Music, Dance and Sports, People, Politics, Religion and Mythology, Time and Schedule, and Transportation. These 14 themes align with Lussier's (2007) description of knowledge as related to "small c" culture. The themes also aligned with many knowledge types mentioned in intercultural knowledge definitions (e.g., products and practices, societal and individual interactions, historical and sociopolitical situations, day-to-day norms and ways of being, the ways in which countries' experiences compare). Alignment between the data and theoretical notions of intercultural knowledge confirms that the goal of this study to investigate intercultural knowledge was achieved and further validates the approach of using L2 data to examine intercultural knowledge development.

While in general all intercultural knowledge themes in Czerwionka et al. (2015) were represented by the students in the Basque Country program, the coded themes in this study go beyond those in Czerwionka et al. (2015) by indicating heightened knowledge about Geography, Identity, Language, Music, Dance and Sports and Religion and Mythology. Student comments indicated knowledge about Geography, mainly geography related to places they visited. As the following comment made by a student in the second interview shows (Comment 19), visiting and experiencing places in person rather than reading about them in a book contribute to the student's learning process. 
Comment 19:

'I am very bad at history and geography, and every time I have to learn from a book, I failed to retain the information. However, since I visited these places, and I was there in person, I can remember their names and historical information. Being there and experiencing it make it easier for me to learn and remember the information.'

The themes Identity, Language, Music, Dance and Sports, and Religion and Mythology reflected knowledge of social groups (Byram, 1997), as students addressed them by identifying and distinguishing Basque ethnicity, culture, and language from Spanish ones. Students pointed out that Basque people had a strong sense of Basque identity, different from the Spanish identity, as well as their own native language, linguistically not related to Spanish. They explained how different the Basque music, dance, and sports were in comparison to the stereotypical Spanish ones, such as flamenco and bullfighting. Further, they talked about the religion that had existed only in the Basque Country before the arrival of Catholicism.

Unlike the current findings, knowledge of social groups was found to be absent from comments by students who participated in the Madrid summer program (Czerwionka et al., 2015). Czerwionka et al. (2015) proposed two explanations for this lack of awareness. First, six weeks was not long enough for students to gain access to the social nuances of the host society. Second, students had not been exposed to the study of social groups in the home or host country, and thus did not have experience seeing or analyzing social groups. They concluded that no matter the reason, the data indicated that interpretation of social groups within a host community during study abroad is challenging for students and the discussion of social groups at times lacks complexity, a finding also indicated by Talburt and Stewart (1999). The results from this study invalidate the first reason while they validate the second. The Basque Country summer program was shorter than the Madrid program, and yet the students gained access to social nuances of the host society related to the minority society of the Basque people within the dominant Spanish society. The relevant factor for the gain of knowledge of social groups was the location of the program, as students need to have experience seeing or analyzing social groups. Since both programs offered a culture course, in which cultures of Spain were equally covered, the presence of the knowledge of social groups did not result from taking the cultural course. Hence, programs in linguistically, ethnically, or culturally diverse areas within a political boundary of a dominant culture (e.g. Spain) highlight intercultural knowledge about social groups.

\section{Change in knowledge}

Two patterns of knowledge change were highlighted: decrease and increase. The first pattern, decrease, happened with the themes City Life and Time and Schedule, which represent sociocultural differences that are easiest to perceive in a matter of days. Students require more exposure to the other areas of knowledge to be capable of perceiving them. This is supported by Czerwionka et al.'s (2015) findings in which City Life and Time and Schedule were also more salient to the students in the first interview. Czerwionka et al. (2015) argued that students in their study had just shifted from a rural, Midwestern, American context to the urban surroundings of Madrid, Spain, which made subthemes of City Life and Schedule particularly salient for them. This context shift also occurred among our students, but instead of shifting from a rural context, they shifted from the urban surroundings of New York City. Thus, students were constantly contrasting an urban area with which they were familiar with the new unfamiliar urban area and the surrounding small towns. Nevertheless, these two themes 
were not as salient for students after having five weeks of experience in the Basque Country, indicating that they relate to cultural ways to which students adjust, a finding that aligns with those in Czerwionka et al. (2015).

The second pattern of knowledge change was observed in Climate and Landscape, Daily Life, Gastronomy, Geography, Identity, Language, Music, Dance and Sports, People, Politics, Religion and Mythology, and Transportation. Students commented more often on subthemes within these themes at the end of the program than at the beginning. This second pattern indicates an increasing salience of the topics over the program.

\section{Knowledge growth}

Students experienced knowledge growth in all 14 themes. However, the greatest intercultural knowledge growth occurred in Music, Dance and Sports and Religion and Mythology: 100\% of the student comments in Interview 2 represented new knowledge in these areas. Other themes involving a great rate of knowledge growth, with between $92.9 \%$ and $81.8 \%$ of comments during Interview 2 being new information, were Gastronomy, Geography, Identity and Language. The most salient subthemes within these themes were strongly linked to the Basque Country, and often indicated the diversity within the context of Spain (see examples in sections 4.3.2. and 4.3.3.).

Hence, there were unique differences in the intercultural knowledge growth associated with the program in the Basque Country. This knowledge growth related specifically to the Basque Country's linguistic, ethnic, and cultural diversity can be explained by the impact of the location of the program. In fact, student comments often indicated overt learning during the program, as they mentioned not knowing about the Basque language or people before participating in the program. Overall, the analysis of knowledge growth supports the thematic analysis indicating that a benefit of study abroad in a minority context is knowledge gains related to the social environment and social groups, in this case the cultural and linguistic minority situation of the Basque people.

\section{Conclusion}

The goal of this investigation was to examine intercultural knowledge development in a shortterm study abroad program in a minority context, for which a pre- and post-program quantitative and qualitative design was used. The quantitative results demonstrated an increase in intercultural knowledge over the five weeks. They also showed that the students began the program with some intercultural knowledge. Thus, study abroad programs provide the potential to gain intercultural knowledge during a short-term program abroad, at least for students who already have some intercultural knowledge. In comparison to prior studies using the same quantitative measure, it was found that study abroad has increased benefits for students beginning with lower levels of intercultural knowledge.

Based on the qualitative data, which allowed for the analysis of intercultural knowledge via the second language, three main results related to intercultural knowledge development were identified. First, students exhibited intercultural knowledge that aligned with Lussier's (2007) description of knowledge as related to "small c" culture during the five-week period. More importantly, they also showed knowledge related to social groups by addressing subthemes about Basque ethnicity, culture, and language, as well as by identifying differences from Spanish ethnicity, culture, and language. Thus, 
the location of the program is fundamental in terms of its impact on intercultural knowledge development, especially related to social groups. Second, students experienced changes in the salience of most intercultural knowledge themes. Based on the current findings and those in prior research, City Life and Time and Schedule differences are easily perceived at the beginning of the program, and students adjust to these differences over the program. Yet, students find the majority of the themes to be more salient at the end of the program. Third, students exhibited intercultural knowledge growth over the period of time spent abroad. The greatest intercultural knowledge growth occurred in subthemes strongly linked to the minority contexts that the Basque Country represents within Spain, further supporting the finding that study abroad in a minority context promotes learning about local social structures, a gap in learning identified in previous literature. Of course, this particular minority context may not fully prepare students to understand all minority contexts in the world or all relationships involving power and privilege, but it serves to expose students to ideas that can be jumping off points for future growth and understanding. In the case of the Basque Country, students learned about ethnicity, a concept that can influence how they understand world relations and conflicts and how they interact with others.

In general, this study offered detailed information about students' intercultural knowledge development, and it confirms that intercultural knowledge can be examined via the second language. Specifically, it demonstrated that programs in linguistically, ethnically, or culturally diverse areas within a political boundary of a dominant culture highlight intercultural knowledge about social groups. Similar findings would be expected in a short-term program that takes place in Galicia or Catalonia, two Spanish autonomous communities with a cultural and linguistic minority context. Yet, future studies should consider the impact of varied minority contexts on students' intercultural knowledge. Whereas the topic of ethnicity was particularly salient in the current data based on the characteristics of the Basque Country, one may find that programs in other minority context that draw attention to social differences of race or socioeconomic class, for example, may impact learners' knowledge differentially. Future studies should also examine intercultural knowledge, along with learners' skills and attitudes, to more fully grasp the impact of study abroad on intercultural communicative competence as a whole.

\section{References}

Bennett, J. M. (1993). Toward ethnorelativism: A developmental model of intercultural sensitivity. In R. M. Paige (Ed.), Education for the intercultural experience ( $2^{\text {nd }}$ ed., pp. 21-71). Yarmouth, ME: Intercultural.

Bennett, J. M. (2008). Transformative training: Designing programs for culture learning. In M. A. Moodian (Ed.), Contemporary leadership and intercultural competence: Understanding and utilizing cultural diversity to build successful organizations (pp. 95-110). Thousand Oaks, CA: Sage.

Black, H. T., \& Duhon, D. L. (2006). Assessing the impact of business study abroad programs on cultural awareness and personal development. The Journal of Education for Business, 81(3), 140-144.

Byram, M. (1997). Teaching and assessing intercultural communicative competence. Bristol, PA: Multilingual Matters Ltd.

Caffi, C., \& Janney, R. (1994). Toward a pragmatics of emotive communication. Journal of Pragmatics, $22,(3-4)$ 325-373.

Chieffo, L., \& Griffiths, L. (2004). Large scale assessment of student attitudes after a short-term study abroad program. Frontiers: The Interdisciplinary Journal of Study Abroad, 10, 165-177.

Collentine, Joseph G. 2004. The effects of learning contexts on morphosyntactic and lexical development. Studies in Second Language Acquisition, 26 (2), 227-48. 
Corbin, J., \& Strauss, A. (2008). Basics of qualitative research: Techniques and procedures for developing grounded theory. Thousand Oaks, CA: Sage.

Czerwionka, L., Artamonova, T. \& Barbosa, M. (2014). "Intercultural competence during short-term study abroad: A focus on knowledge." In B. Dupuy \& L. Waugh (Eds.), Selected Proceedings of the Fourth International Conference on the Development and Assessment of Intercultural Competence, 3, 46-77.

Czerwionka, L. Artamonova, T. \& Barbosa, M. (2015). Intercultural knowledge development: Evidence from student interviews during short-term study abroad. International Journal of Intercultural Relations, 49, 80-99.

Deardorff, D. (2006). Identification and assessment of intercultural competence as a student outcome of internationalization. Journal of Studies in International Education, 10(3), 241-266.

DeKeyser, R. 1990. From learning to acquisition? Monitoring in the classroom and abroad. Hispania, 73, 238-47.

Dings, A. (2007). Developing interactional competence in a second language: A case study of a Spanish language learner. (Unpublished doctoral dissertation). University of Texas, Austin.

Dings, A. (2014). Interactional competence and the development of alignment activity. The Modern Language Journal, 98 (3), 742-756.

Dwyer, M. M. (2004). More is better: The impact of study abroad program duration. Frontiers: The Interdisciplinary Journal of Study Abroad, 10, 151-163.

Eckert, P. (2000). Linguistic variation as social practice. Oxford: Blackwell.

Elola, I., \& Oskoz, A. (2008). Blogging: Fostering intercultural competence development in foreign language and study abroad contexts. Foreign Language Annals, 41(3), 454-477.

Engle, L., \& Engle, J. (2004). Assessing language acquisition and intercultural sensitivity development in relation to study abroad program design. Frontiers: The Interdisciplinary Journal of Study Abroad, 10, 219-236.

Fantini, A., \& Tirmizi, A. (2006). Exploring and assessing intercultural competence. World Learning Publications, Paper 1. Retrieved from http://digitalcollections.sit.edu/worldlearning_publications/1

Gertsen, M. (1990). Intercultural competence and expatriates. International Journal of Human Resources Management, 1(3), 341-362.

Glaser, B., \& Strauss, A. (1967). The discovery of grounded theory: Strategies for qualitative research. New York: Aldine.

Gudykunst, W., Ting-Toomey, S., \& Wiseman, R. (1991). Taming the beast: Designing a course in intercultural communication. Communication Education, 40 (3), 272-285.

Jackson, J. (2011). Host language proficiency, intercultural sensitivity, and study abroad. Frontiers: The Interdisciplinary Journal of Study Abroad, 21, 167-188.

Jessup-Anger, J. E. Gender observations and study abroad: How students reconcile cross-cultural differences related to gender. Journal of College Student Development, 49(4) 360-373.

Kinginger, C. (2008). Language learning in study abroad: Case studies of Americans in France. The Modern Language Journal Monograph Series, 1. Oxford: Blackwell.

Lafford, B. F. (1995). Getting into, through and out of a survival situation: A comparison of communicative strategies used by students studying Spanish abroad and 'at home.' In B. F. Freed (Ed.), Second language acquisition in a study abroad context (pp. 97-121). Philadelphia: John Benjamins.

le Roux, J. (2002). Effective educators are culturally competent communicators. Intercultural Education, 13(1), 37-48.

Lussier, D. (2007). Theoretical bases of a conceptual framework with reference to intercultural communicative competence. Journal of Applied Linguistics, 4(3), 309-332.

Malmgren, J., \& Galvin, J. Effects of study abroad participation on student graduation rates: A study of three incoming freshman cohorts at the University of Minnesota, Twin Cities. NACADA Journal, 28(1), 29-42.

Martinsen, R. (2011). Predicting changes in cultural sensitivity during short-term study abroad. Hispania, $94(1), 121-141$.

Risager, K. (2007). Language and culture pedagogy: From a national to a transnational paradigm. 
Buffalo, NY: Multilingual Matters.

Ruben, B.D. (1976). Assessing communication competency for intercultural adaptation. Group and Organization Studies, 1, 334-354.

Segalowitz, N., \& Freed, B. F. (2004). Context, contact, and cognition in oral fluency acquisition: Learning Spanish in at home and study, Studies in Second Language Acquisition 26 (2), 173-199

Stier, J. (2006). Internationalisation, intercultural communication and intercultural competence. Journal of Intercultural Communication, 11, 1-12

Tagliamonte, S. A. (2006). Analysing sociolinguistic variation. Cambridge: Cambridge University Press.

Talburt, S., \& Stewart, M. A. (1999). What's the subject of study abroad: Race, gender, and "living culture." The Modern Language Journal, 83(2), 163-175.

The Institute of International Education. Open doors report. Retrieved from http://www.iie.org/opendoors Ting-Toomey, S. (1999). Communicating across cultures. New York, NY: The Guilford Press.

Twombly, S. B. (1995). Piropos and friendships: Gender and culture clash in study abroad. Frontiers: The Interdisciplinary Journal of Study Abroad, 1, 1-27.

Vande Berg, M., Paige, M. R., \& Lou, K. H. (Eds.). (2012). Student learning abroad: What our students are learning, what they're not, and what we can do about it. Sterling, VA: Stylus.

Williams, T. R. (2009). The reflective model of intercultural competency: A multidimensional, qualitative approach to study abroad assessment. Frontiers: The Interdisciplinary Journal of Study Abroad, 18, 289-306.

Wiseman, R. (2002). Intercultural communication competence. In W.B. Gudykunst \& B. Mody (Eds.), Handbook of international and intercultural communication (pp. 207-224). Thousand Oaks, CA: Sage Publications

Wiseman, R., Hammer, M., \& Nishida, H. (1989). Predictors of intercultural communication competence. International Journal of Intercultural Relations, 13 (3), 349-370.

\section{Appendix A}

Survey Instrument with Subscales of Intercultural Knowledge

1. I can cite a definition of culture and describe its components and complexities.

\begin{tabular}{|l|l|l|l|l|l|l|}
\hline 1 & 2 & 3 & 4 & 5 & 6 & 7 \\
\hline
\end{tabular}

2. I know the essential norms and taboos of the host culture (e.g. greetings, dress, behaviors, etc.)

\begin{tabular}{|l|l|l|l|l|l|l|}
\hline 1 & 2 & 3 & 4 & 5 & 6 & 7 \\
\hline
\end{tabular}

3. I can contrast important aspects of the host language and culture with my own.

\begin{tabular}{|l|l|l|l|l|l|l|}
\hline 1 & 2 & 3 & 4 & 5 & 6 & 7 \\
\hline
\end{tabular}

4. I recognize signs of culture stress and some strategies for overcoming it.

\begin{tabular}{|l|l|l|l|l|l|l|}
\hline 1 & 2 & 3 & 4 & 5 & 6 & 7 \\
\hline
\end{tabular}

5. I know some techniques to aid my learning of the host language and culture.

\begin{tabular}{|l|l|l|l|l|l|l|}
\hline 1 & 2 & 3 & 4 & 5 & 6 & 7 \\
\hline
\end{tabular}

6. I can contrast my own behaviors with those of my hosts in important areas (e.g. social interactions, basic routines, time orientation, etc.)

\begin{tabular}{|l|l|l|l|l|l|l|}
\hline 1 & 2 & 3 & 4 & 5 & 6 & 7 \\
\hline
\end{tabular}

7. I can cite important historical and socio-political factors that shape my own culture and the host culture.

\begin{tabular}{|l|l|l|l|l|l|l|}
\hline 1 & 2 & 3 & 4 & 5 & 6 & 7 \\
\hline
\end{tabular}


8. I can describe a model of cross-cultural adjustment stages.

\begin{tabular}{|l|l|l|l|l|l|l|}
\hline 1 & 2 & 3 & 4 & 5 & 6 & 7 \\
\hline
\end{tabular}

9. I can cite various learning processes and strategies for learning about and adjusting to the host culture.

\begin{tabular}{|l|l|l|l|l|l|l|}
\hline 1 & 2 & 3 & 4 & 5 & 6 & 7 \\
\hline
\end{tabular}

10. I can describe interactional behaviors common among Basques in social and professional areas (e.g. family roles, team work, problem solving, etc.).

\begin{tabular}{|l|l|l|l|l|l|l|}
\hline 1 & 2 & 3 & 4 & 5 & 6 & 7 \\
\hline
\end{tabular}

11. I can discuss and contrast various behavioral patterns in my own culture with those in the Basque Country.

\begin{tabular}{|l|l|l|l|l|l|l|}
\hline 1 & 2 & 3 & 4 & 5 & 6 & 7 \\
\hline
\end{tabular}

Appendix B

Semi-structured interview guide

Introduction

How are you? How's the week? Where are you from? What's your city or town like?

¿Cómo estás? ¿Qué tal la semana? ¿De dónde eres? ¿Y cómo es tu pueblo/ciudad?

University

Interview 1: What classes do you have this summer? What are they like?

¿Qué clases tienes este verano? ¿Cómo son?

Interview 2: What have you learned this summer? Of your classes, which has been the easiest, the hardest?

¿Qué has aprendido en tus clases este verano? De las clases este verano ¿cuál ha sido la más fácil, la más difícil?

Family

What's your family like in the United States? What's your family like in Bilbao? How does your Bilbao family compare to your family in the United States?

¿Cómo es tu familia en los Estados Unidos? ¿Cómo es tu familia en Bilbao? ¿Cómo se compara la familia en Bilbao con tu familia en los Estados Unidos?

Living arrangements and life

How does the house in Bilbao compare to your house in the United States?

¿Cómo se compara la casa en Bilbao con tu casa en los Estados Unidos?

Opinions and cultural comparisons

What do you think of the Basque Country?

¿Qué opinas sobre el País Vasco?

What things or aspects of life in the United States do you like, and which don't you like? What are elements of Basque life that you like, and which don't you like? How do the two places compare to one another?

¿Qué cosas o aspectos de la vida te gustan y no te gustan de los Estados Unidos? ¿Qué son elementos de la vida vasca que te gustan y no te gustan? ¿Cómo se comparan los dos lugares? People 
Of the people that you've met, what do you think? With whom do you talk in Spanish? What have you noticed about interactions between people? What is a Basque person like in your opinion?

¿Y de la gente que has conocido, qué opinas? ¿Con quién hablas el español? ¿Qué has notado de las interacciones entre las personas? ¿Cómo es una persona vasca en tu opinión?

Adjustment and personality

Interview 1: In these six weeks, what do you hope to learn about yourself?

En estas 6 semanas ¿Qué esperas aprender sobre ti mismo/a?

Interview 2: In these six weeks, what have you learned about yourself?

En estas 6 semanas ¿Qué has aprendido sobre ti mismo/a?

Feelings, achievements, and advice

Have you experienced something fun here in the Basque Country? Why did you want to participate in this program? Do you think that you achieved these things? What kind of advice would you give to someone who wants to come to the Basque Country next year?

¿Te ha pasado algo divertido aquí en el País Vasco? ¿Por qué querrías participar en este programa? ¿Sientes que has logrando esas cosas? ¿Qué consejo le darías a alguien que quiere venir el próximo año al País Vasco?

Appendix C

Number of student mentions by theme and subtheme.

\begin{tabular}{|c|c|c|c|}
\hline Themes & $(n)$ & Subthemes & $(n)$ \\
\hline \multirow[t]{15}{*}{ City Life } & $(106)$ & Streets & (19) \\
\hline & & Buildings & $(16)$ \\
\hline & & Monuments/museums & $(15)$ \\
\hline & & Size & (14) \\
\hline & & House type & (10) \\
\hline & & Flags & $(8)$ \\
\hline & & Safety & $(5)$ \\
\hline & & Police & $(4)$ \\
\hline & & Txosnas3 & (3) \\
\hline & & Walk & (3) \\
\hline & & Bars/restaurants & $(2)$ \\
\hline & & Cost & $(2)$ \\
\hline & & Nightlife & $(2)$ \\
\hline & & Tourists & $(2)$ \\
\hline & & Driving direction & $(1)$ \\
\hline \multirow[t]{4}{*}{ Climate and Landscape } & (17) & Weather & (12) \\
\hline & & Sea temperature & (3) \\
\hline & & Landscape & $(1)$ \\
\hline & & Wealth & (1) \\
\hline Daily Life & $(106)$ & Speed & (31) \\
\hline
\end{tabular}

3 The txosna is a tavern that is assembled at regional parties in the Basque Country and Navarre. 


\begin{tabular}{|c|c|c|c|}
\hline & & Modes of socialization & (14) \\
\hline & & Naps & (14) \\
\hline & & Fashion & (10) \\
\hline & & Parties/celebrations & $(6)$ \\
\hline & & Eating with companion/s & $(6)$ \\
\hline & & Social places & $(5)$ \\
\hline & & Walking & $(5)$ \\
\hline & & Topless & $(4)$ \\
\hline & & Smoking & $(4)$ \\
\hline & & Rules & $(2)$ \\
\hline & & Violence & $(2)$ \\
\hline & & Free time & (1) \\
\hline & & Housework & $(1)$ \\
\hline & & Noise & (1) \\
\hline Gastronomy & $(103)$ & Preparation/ingredients & (19) \\
\hline & & Traditional Basque food & (19) \\
\hline & & Pintxos & $(18)$ \\
\hline & & Tapas & (11) \\
\hline & & Always Bread & $(8)$ \\
\hline & & Cost & $(6)$ \\
\hline & & Size/Portions & $(6)$ \\
\hline & & Type of breakfast & $(5)$ \\
\hline & & Culture & $(4)$ \\
\hline & & Healthy & $(4)$ \\
\hline & & Traditional Basque drinks & $(3)$ \\
\hline Geography & $(56)$ & Internationally known cities & (19) \\
\hline & & Towns & (14) \\
\hline & & Cities & $(9)$ \\
\hline & & Autonomous Communities & $(8)$ \\
\hline & & Beaches & $(6)$ \\
\hline Identity & $(46)$ & Diversity & $(17)$ \\
\hline & & Basque identity & $(9)$ \\
\hline & & Basque fashion & $(7)$ \\
\hline & & Basque culture & $(4)$ \\
\hline & & Catalans & $(4)$ \\
\hline & & Cliché & $(4)$ \\
\hline & & Galicians & (1) \\
\hline Interactions & $(46)$ & Direct & (10) \\
\hline & & Greetings & $(10)$ \\
\hline & & Personal space & $(10)$ \\
\hline & & Tone & $(6)$ \\
\hline & & Closer & $(5)$ \\
\hline & & Galician way & $(4)$ \\
\hline
\end{tabular}




\begin{tabular}{|c|c|c|c|}
\hline \multirow{15}{*}{ Language } & & Touchy & (1) \\
\hline & \multirow[t]{14}{*}{ (85) } & Basque linguistics & $(18)$ \\
\hline & & Spanish dialectology & $(17)$ \\
\hline & & Euskera & (11) \\
\hline & & Basque expressions/words & $(10)$ \\
\hline & & Basque use & $(8)$ \\
\hline & & Local expressions/words & $(6)$ \\
\hline & & Linguistic diversity in Spain & (4) \\
\hline & & Bilingualism & (3) \\
\hline & & Spanish linguistics & (3) \\
\hline & & Speed & (1) \\
\hline & & English knowledge & (1) \\
\hline & & Impossible Translations & (1) \\
\hline & & Spanish as the only language in Spain & $(1)$ \\
\hline & & Basque language preservation & $(1)$ \\
\hline \multirow[t]{6}{*}{ Music, Dance and Sports } & \multirow[t]{6}{*}{$(28)$} & Basque Sports & (9) \\
\hline & & Dance Cliché & (6) \\
\hline & & Latin music & (4) \\
\hline & & Basque Dance & (4) \\
\hline & & Football & (4) \\
\hline & & Dance diversity & (1) \\
\hline \multirow[t]{19}{*}{ People } & \multirow[t]{19}{*}{ (157) } & Nice/friendly & $(27)$ \\
\hline & & Ethnicity & $(24)$ \\
\hline & & Relaxed & (13) \\
\hline & & Stereotypes & $(12)$ \\
\hline & & Talkative & $(10)$ \\
\hline & & Family & $(10)$ \\
\hline & & Sociable & (9) \\
\hline & & Group of friends & (9) \\
\hline & & Physical appearance & $(8)$ \\
\hline & & Interests/pleasures & (7) \\
\hline & & Trusting/honest & $(5)$ \\
\hline & & Gender difference & $(5)$ \\
\hline & & Happy & (4) \\
\hline & & Collaborative & (4) \\
\hline & & Green & (3) \\
\hline & & Healthy & (3) \\
\hline & & Basque people don't dance & (2) \\
\hline & & Straight & (1) \\
\hline & & Proud & $(1)$ \\
\hline \multirow{3}{*}{ Politics } & \multirow{3}{*}{$(57)$} & Basque nationalism & $(20)$ \\
\hline & & Liberals & $(16)$ \\
\hline & & 18 to drink alcohol & $(8)$ \\
\hline
\end{tabular}






Appendix D

Number of student mentions indicating knowledge growth by theme and subtheme.

\begin{tabular}{llll}
\hline Themes & $(n)$ & Subthemes & $(n)$ \\
\hline City Life & $(20)$ & Flags & $(8)$ \\
& & Safety & $(4)$ \\
& & Txosnas & $(2)$ \\
& & Nightlife & $(2)$ \\
& & Walk & $(2)$ \\
& & Tourists & $(2)$ \\
& & Sea temperature & $(3)$ \\
Climate and Landscape & (7) & Weather & $(2)$ \\
& & Landscape & $(1)$ \\
& & Wealth & $(1)$ \\
& & Speed & $(9)$ \\
& & Modes of socialization & $(6)$ \\
Daily Life & $(37)$ & Fashion & $(6)$ \\
& & Eating in companion & $(6)$ \\
& & Parties/celebration & $(2)$ \\
& & Naps & $(2)$ \\
& & Rules & $(2)$ \\
& & Violence & $(2)$ \\
& & Walking & $(1)$ \\
& & Noise & $(1)$
\end{tabular}




\begin{tabular}{|c|c|c|c|}
\hline \multirow[t]{7}{*}{ Gastronomy } & \multirow[t]{7}{*}{ (63) } & Pintxos & $(18)$ \\
\hline & & Preparation/ingredients & (13) \\
\hline & & Traditional food & (13) \\
\hline & & Always Bread & $(8)$ \\
\hline & & Cost & $(6)$ \\
\hline & & Traditional drink & $(3)$ \\
\hline & & Size/Portions & $(2)$ \\
\hline \multirow[t]{4}{*}{ Geography } & \multirow[t]{4}{*}{$(33)$} & Towns & (14) \\
\hline & & Cities & $(9)$ \\
\hline & & Autonomous Communities & $(8)$ \\
\hline & & Beaches & (2) \\
\hline \multirow[t]{7}{*}{ Identity } & \multirow[t]{7}{*}{$(42)$} & Diversity & $(15)$ \\
\hline & & Basque identity & $(7)$ \\
\hline & & Basque fashion & $(7)$ \\
\hline & & Basque culture & $(4)$ \\
\hline & & Catalans & (4) \\
\hline & & Cliché & $(4)$ \\
\hline & & Galicians & (1) \\
\hline \multirow[t]{3}{*}{ Interactions } & \multirow[t]{3}{*}{ (12) } & Tone & $(6)$ \\
\hline & & Galician way & (4) \\
\hline & & Direct & $(2)$ \\
\hline \multirow[t]{8}{*}{ Language } & \multirow[t]{8}{*}{$(65)$} & Basque linguistics & $(18)$ \\
\hline & & Spanish dialectology & (13) \\
\hline & & Basque expressions/words & $(10)$ \\
\hline & & Basque use & $(8)$ \\
\hline & & Local expressions/words & $(6)$ \\
\hline & & Euskera & $(5)$ \\
\hline & & Linguistic diversity in Spain & $(4)$ \\
\hline & & Basque language preservation & $(1)$ \\
\hline \multirow[t]{6}{*}{ Music, Dance and Sports } & \multirow[t]{6}{*}{$(28)$} & Basque Sports & $(9)$ \\
\hline & & Dance Cliché & $(6)$ \\
\hline & & Latin music & $(4)$ \\
\hline & & Basque Dance & $(4)$ \\
\hline & & Football & (4) \\
\hline & & Dance diversity & $(1)$ \\
\hline \multirow[t]{8}{*}{ People } & \multirow[t]{8}{*}{ (61) } & Ethnicity & (12) \\
\hline & & Stereotypes & (12) \\
\hline & & Family & $(10)$ \\
\hline & & Group of friends & (9) \\
\hline & & Relaxed & (5) \\
\hline & & Gender difference & (5) \\
\hline & & Healthy & (3) \\
\hline & & Basque people don't dance & (2) \\
\hline
\end{tabular}




\begin{tabular}{|c|c|c|c|}
\hline & & Sociable & (1) \\
\hline & & Trusting/honest & (1) \\
\hline & & Proud & (1) \\
\hline \multirow[t]{7}{*}{ Politics } & $(33)$ & Basque nationalism & $(20)$ \\
\hline & & Liberals & (4) \\
\hline & & Catalan nationalism & (4) \\
\hline & & Relaxed laws/police & (2) \\
\hline & & Healthcare system & (1) \\
\hline & & Political discussions & (1) \\
\hline & & Diversity & (1) \\
\hline \multirow[t]{3}{*}{ Religion and Mythology } & $(10)$ & Basque mythology & $(7)$ \\
\hline & & Catholicism & (2) \\
\hline & & Traditions/beliefs & (1) \\
\hline Time and Schedule & (3) & Stores close & (3) \\
\hline \multirow[t]{3}{*}{ Transportation } & (8) & There is public transportation & (4) \\
\hline & & Efficient & (3) \\
\hline & & Clean & (1) \\
\hline
\end{tabular}

